\title{
In Vitro Radiosensitivity of Adamantinomatous Craniopharyngiomas
}

\author{
Elfar úlfarsson ${ }^{1 *}$, Margareta R Edgren ${ }^{2}$, Alexandr Karström ${ }^{3}$ and Ingmar Lax ${ }^{2,4}$ \\ ${ }^{1}$ Department of Neurosurgery, Landspitali University, Iceland \\ ${ }^{2}$ Department of oncology-pathology, Karolinska University Hospital, Sweden \\ ${ }^{3}$ Department of Plastic Surgery, Uppsala University Hospital, Sweden \\ ${ }^{4}$ Hospital Physics, Karolinska University Hospital, Sweden
}

Submission: November 01, 2016; Published: December 15, 2016

*Corresponding author: Elfar úlfarsson, Department of Neurosurgery, Landspitali University Hospital Fossvogi, 108 Reykjavík, Iceland, fax +354 5437695; Email: elfarulf@landspitali.is

\begin{abstract}
Summary
Background and purpose: Improvements in radiation treatment for craniopharyngiomas are needed. No clear in vivo data exists on radiosensitivity of craniopharyngiomas and in vitro data is lacking. The purpose of this study was to assess the radiosensitivity of adamantinomatous craniopharyngioma in vitro.

Material and methods: Craniopahryngioma cells from 7 individuals (two different passage number) were seeded in triplicate wells and exposed to 8 photon doses in the range $0-10 \mathrm{~Gy}$ in a ${ }^{137} \mathrm{Cs}$ irradiation chamber. The radiosensitivity was measured as clonogenic cell survival. The surviving fraction at 2 Gy (SF2), the mean inactivation dose $\bar{D}$ and the $\alpha / \beta$ ratios were calculated from the dose response curve fitted with the Linear Quadratic model.

Results: The SF2, and $\alpha / \beta$ values for the cell strains ranged from 0.31 to $0.47,1.65$ to 2.44 and 10 to 30 Gy, respectively. The mean, standard deviation and coefficient of variation of the $S F 2$, and $\alpha / \beta$ values were $0.40 \pm 0.07,17 \%, 2.04 \pm 0.30,15 \%$ and $19 \pm 6 \mathrm{~Gy}, 33 \%$, respectively.

Conclusion: The high $\alpha / \beta$ value indicates that adamantinomatous craniopharyngioma is among early responding tissues. This supports the clinical praxis of fractionated radiation for those tumors.
\end{abstract}

Keywords: Craniopharyngioma; Radiosensitivity, Clonogenic cell survival, Alpha/beta ratio, radiation treatment

\section{Introduction}

Craniopharyngioma is a benign neoplasm of epithelial origin located in the sellar and suprasellar region. The adamantinomatous craniopharyngioma represents around $2 / 3$ of all craniopharyngiomas and is the most common pathology in this region in children [1,2]. Other histological subtypes are the squamous papillary and the xanthogranulomatous type [3]. The former occurs almost exclusively in adults. The main treatment options are surgery and conventional radiotherapy (CRT). Surgical cure is hampered by the eloquent surrounding structures and is accomplished in few cases. The acknowledgement of the devastating effect of hypothalamus damage on quality of life has led to more conservative surgery and increased use of adjuvant RT in children [4,5]. CRT has proved its value in controlling craniopharyngiomas; however considerable irradiation to the surrounding tissues is unavoidable by this technique and not without sacrifices.

The decline in intellectual function in children [6], inability to treat the youngest patient group, radiation induced malignant gliomas [7] and 10-years recurrent free survival rates of $32 \%$ $49 \%[8,9]$ in children stresses the limits in the current CRT.

Gamma Knife radiosurgery (GKRS) has been used as an alternative to CRT to reduce the radiation load on the surrounding tissues. Reports on low morbidity from the anterior visual pathways using this technique, 3.1\%(10), underlines the power of photon beam focusing. The main drawbacks are the target volume restrictions and higher risk of geometrical misses compared to CRT. The ultimate limitation of the single session 
GKRS is that the most effective GKRS-dose, 11.7 - 12.7 Gy, is also the critical toxicity dose for the anterior visual pathway $[10,11]$.

The majority of craniopharyngioma patients receive radiation treatment during their diseased life and around one third of them experience tumor progress [12]. The hazard of repeated irradiation precludes further radiation in most cases and the danger of repeated surgical trauma is well known. The gravity of the situation of late recurrences is reflected in a very high mortality after salvage treatment $[13,14]$. Thus, improvement in the radiation treatment is clearly needed. No clear data exists on the radiosensitivity of craniopharyngiomas and the optimal dose has not been defined. The lack of detailed dose-response data and standardized way of reporting endpoints disables a thorough interpretation of radiobiological data from the literature. Furthermore in vitro radiosensitivity data, that could be useful in designing new fractionation regimens, is lacking.

The purpose of this study is first to assess the in vitro radiosensitivity of adamantinomatous craniopharyngiomas and second to address the alpha beta ratio $(\alpha / \beta)$ specifically from a clinical perspective.

\section{Methods and Materials \\ Cell cultures}

Primary cultures of human craniopharyngioma cells were isolated and prepared from tumour samples in a similar manner as for keratinocytes according to the methods described elsewhere $[15,16]$. The obtained cultures used for the (irradiation) experiments were plated without feeder cells in passages between 3 and 9 (median 5). All patients harboured histological verified adamantinomtous type of craniopharyngioma. The procedures were in accordance with the ethical standards of the institutional committee on human experimentation and with the Helsinki Declaration of 1975, as revised in 2000.

\section{Clonogenic survival}

Appropriate cell numbers were plated for survival using the clonogenic assay technique described previously [17]. The single-cell suspensions were plated into $35 \mathrm{~mm}$ plastic petri dishes (Corning, New York) in triplicates to a final medium volume of $3 \mathrm{ml}$ and then left in the incubator for 3-4 h to attach before irradiation.

The cells were irradiated at room temperature with doses of 0-10 Gy at a dose rate of $0.5 \mathrm{~Gy} / \mathrm{min}$ from a ${ }^{137} \mathrm{Cs}$-source (Scanditronix, Uppsala, Sweden). The cultures were then incubated for 10-14 days, with a change of medium after 5-7 days. Thereafter colonies were fixed, stained and counted. Radiation survival curves were constructed from two independent experiments. The mean PE for un-irradiated cells was 43, 55, 85, $12,10,42$ and $36 \%$ for case 1 to 7 , respectively.

Dose-response models for clonogenic cell survival. The LQ model(18) was used to fit the data with the Maximum Likelihood method, where the probability for clonogenic cell survival $S$ at a dose $D$ is given by [19]:

$$
S=e^{-\left(\alpha D+\beta D^{2}\right)}
$$

The surviving fraction at 2 Gy (SF2) was computed from the whole survival curve and was used as a unique measure of cellular radiation sensitivity. The mean inactivation dose, $\bar{D}$, was calculated according to Taylor [20]. The $\bar{D}$ was chosen since it has been shown to keep the scattering of data smaller than for other parameters such as SF2 and D0 [21].

\section{Assessment of $\alpha / \beta$ in vivo}

From in vivo data, the LQ model can be used to calculate the $\alpha / \beta$ from isoeffective fractionation regimens. This is based on the assumption that the biological effective dose (BED) is the same if two fractionation regimens result in an equivalent clinical effect [22]. In this study, the same tumour control rates were assumed with 2.0 Gy daily fractions with a total dose of 50 Gy [23] and 11.5 Gy prescription dose at the 50\% isodose line using GKRS [10]. For the GKRS, it was assumed as a first reasonable approximation, that the tumor response was related to the mean dose to the tumor which is generally $30-50 \%$ higher than the dose to the periphery. Thus for a prescribed dose of $11.5 \mathrm{~Gy}$, the mean dose will be in the range from $15 \mathrm{~Gy}$ to $17 \mathrm{~Gy}$. Calculation were done for two cases; 1 ) without- and with correction for repopulation during the time of fractionated treatment, in the second case, two values of Tk (the time after start of the treatment when repopulation starts) were used; for keratinocyte-related malignancies such as head and neck tumors ( $\mathrm{Tk}=21$ days) and craniopharyngioma related normal tissues such as mucosa ( $\mathrm{Tk}=7$ days) [24]. For each of the two Tk values, the cell doubling time ( $\mathrm{Tp}$ ) was estimated in patient $\mathrm{C} 1$ and C2using the formula

$$
\mathrm{Tp}=0.693 * t / \ln \left(\mathrm{N}_{\mathrm{t}} / \mathrm{N}_{0}\right) .
$$

\section{Results}

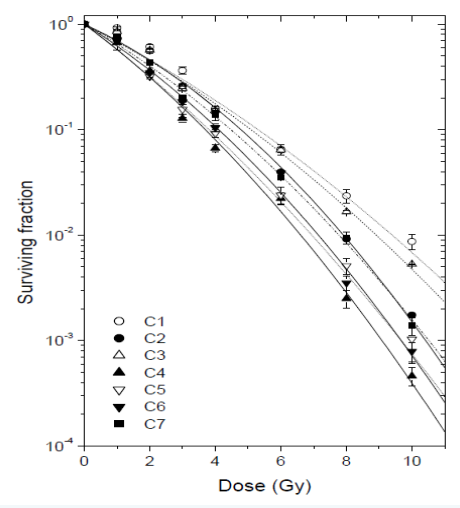

Figure 1: Clonogenic survival curves for 7 craniopharyngioma cell strains as a function of single absorbed doses. The experimental data are fitted to the LQ survival model. Error bars indicate S.E. 


\section{Open Access Journal of Neurology \& Neurosurgery}

The clonogenic cell survival curves and the radiosensitivity parameters from the seven craniopharyngioma cell strains are presented in Figure 1 and Table 1, respectively. The mean values and the coefficient of variation (CV) for SF2 and $\bar{D}$ were 0.401 (SE +/- 0.021) and 2.04 (SD +/- 0.08) and 17\% and 15\%, respectively. The $\alpha / \beta$ value ranged from 10.3 to $29.9 \mathrm{~Gy}$ with $\mathrm{CV}$ of $33 \%$. The mean value was 19 Gy (SE +/- 2.4). Acknowledging the fact that other survival models will fit the data in the lower dose region better, we used the entire dose range when fitting the data. This was done since doses in the range of 8-13Gy are being used for these types of tumors.

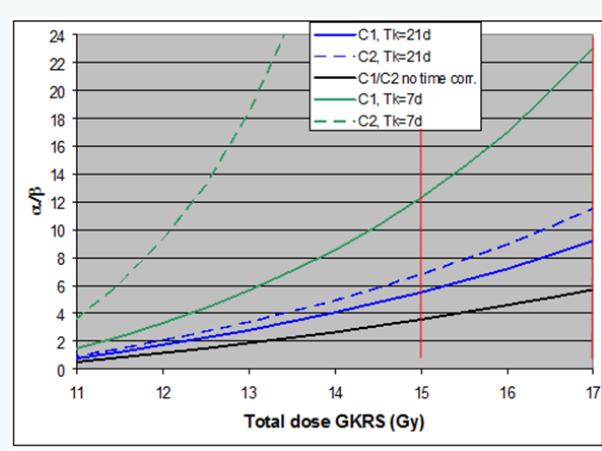

Figure 2: Calculated alfa-beta ratio $(\alpha / \beta)$ versus total dose given by GKRS. Tp and $\alpha$ values used for $\mathrm{C} 1$ were 2.24 days and 0.349 and for $\mathrm{C} 2,1.78$ days and 0.328 .

In Figure $2, \alpha / \beta$ values are given as a function of the mean dose to the tumor in GKRS Estimated mean doses to the tumor, for a prescription dose of 11.5 Gy will be in the range from 15 Gy to $17 \mathrm{~Gy}$. Results are shown, without correction for repopulation, as well as corrected with two Tk values, with two sets of Tp and $\alpha$ values.

Table 1: Parameters from the clonogenic survival curves are shown. Mean values from two repeat experiments for each case are indicated.

\begin{tabular}{|c|c|c|c|c|c|c|}
\hline Case & $\boldsymbol{\alpha}\left(\mathbf{G y}^{-1}\right)$ & $\boldsymbol{\beta}\left(\mathbf{G y}^{-2}\right)$ & $\boldsymbol{\alpha} / \boldsymbol{\beta}(\mathbf{G y})$ & $\mathbf{S F 2}$ & ${ }^{\mathrm{a}} \mathbf{D}(\mathbf{G y})$ & ${ }^{\mathbf{b}} \bar{D}(\mathbf{G y})$ \\
\hline 1 & 0.3492 & 0.0145 & 24.1 & 0.471 & 9.51 & 2.44 \\
\hline 2 & 0.3282 & 0.0322 & 10.3 & 0.457 & 7.91 & 2.23 \\
\hline 3 & 0.3273 & 0.0266 & 14.6 & 0.468 & 8.45 & 2.44 \\
\hline 4 & 0.5294 & 0.0254 & 20.8 & 0.313 & 6.60 & 1.65 \\
\hline 5 & 0.5210 & 0.0187 & 29.9 & 0.328 & 7.10 & 1.73 \\
\hline 6 & 0.4427 & 0.0274 & 16.4 & 0.371 & 7.20 & 1.88 \\
\hline 7 & 0.4057 & 0.0249 & 19.3 & 0.403 & 7.73 & 2.03 \\
\hline Mean & 0.4148 & 0.0242 & 19.3 & 0.401 & 7.79 & 2.04 \\
\hline SE & \pm 0.0269 & \pm 0.0026 & \pm 2.4 & \pm 0.021 & \pm 0.21 & \pm 0.08 \\
\hline $\mathrm{CV}(\%)$ & 21 & 24 & 33 & 17 & 12 & 15 \\
\hline
\end{tabular}

aDose to achieve $1 \%$ survival (S); ${ }^{\mathrm{b}}$ Mean inactivation dose (Dbar)

\section{Discussions}

In this study we present a novel data set on radiosensitivity of adamantinomatous craniopharyngioma cell strains, based on clonogenic survival assays. More than 25 years ago Fertil et al. [25] pointed out a correlation between the radiosensitivity of human cancer cell lines in vitro and the radiocurability of the corresponding tumor types in vivo. Since then histological groups of human cell lines have been characterized by an intrinsic radiosensitivity in vitro [26,27] and this data has been shown to be useful in predicting tumour response to RT [28].

The high variation of $\alpha / \beta$ within specific tumor group as for adamantinomatous craniopharyngiomas in this study is commonly noted in reports for different human cancer lines in vitro. Taghian et al. [29] reported data on glioblastoma, which is among the most radioresistant tumours. The $\alpha / \beta$ ranged from 3.7 to 48 Gy. Weichselbaum et al. [30] reported mean $\alpha / \beta$ for human cancer cell lines with large SD values, reflecting a high variation within each tumour group.

According to SF2 and $\bar{D}$ craniopharyngiomas cell strains are slightly more radiosensitive than the average radiosensitive cancer cell line [27] and the variation is not higher than reported in other cancer cell lines [21,27]. Comparative in vitro data for other benign intracranial tumours is lacking. However, from in vivo data, and with the method used here $\alpha / \beta$ for meningiomas and vestibularis schwannomas have been calculated to be 3.3 Gy and 2-3 Gy, respectively [31]. In this study, the $\alpha / \beta$ will be in the range of 4-6 Gy for adamantinomatous craniopharyngiomas, without correction for repopulation and from 6 Gy to more than 20 Gy if reasonable parameters for correction for repopulation are applied (Figure 2). Those values are still much lower than the in vitro values in this study. The reason for this discrepancy could be explained by a lack of correlation between the in vivo and in vitro data, by paucity of reliable in vivo data or both.

Arguments for craniopharyngiomas having high $\alpha / \beta$ can be found when growth kinetics is considered. It is known that the growth kinetics of the tissue irradiated dominates the radiation response. A higher proliferation indices [32-35] and more dramatic response to irradiation [10,36-39] compared to meningiomas and acustic neurinomas support our findings of a high $\alpha / \beta$ for craniopharyngiomas. The $\alpha / \beta$ for cranipharyngioma related tissues, such as mucosa and epithelium is in the range for early responding tissues or 7 - 15 Gy [40-42]. Since there is often a close similarity between the mean lethal dose of tumour and the normal tissues from which they arise, it is likely that $\alpha / \beta$ for cranipharyngioma is in this high range. If this is the case, one should consider the repopulation time factor in calculating the $\alpha / \beta$ from clinical data. This results in higher $\alpha / \beta$ values (Figure 2) $[43,44]$.

The above estimations of $\alpha / \beta$ values based on in vivo data have to be viewed with caution since the differences in patient and treatment characteristics between clinical studies make it difficult to compare results from different radiation regimens. The main obstacle is that certain parameters that can influence endpoints, such as histological subtypes and tumour volume, are generally not considered in reports on treatment results. 


\section{Open Access Journal of Neurology \& Neurosurgery}

The comparison of iso effective doses for GKRS and CRT could be flawed by differences in tumour volumes treated with those techniques. The general principle is that large tumours (more clonogenic cells) require higher doses than small ones (fewer clonogenic cells) to obtain the same tumour control probability (all clonogenic cells killed, Figure 1). This is also partly explained by the differences in micro-environment between large and small tumors [45,46]. The lack of information on tumour size is more a rule than an exception in studies using CRT for craniopharyngiomas. In viewing the few studies available, it seems that the tumour volume tends to be substantially larger in the CRT studies compared to GKRS studies [10,47-49]. This is a reasonable assumption regarding the radiobiological volume restrictions of GKRS. The implication of this phenomenon in CRT for craniopharyngioma is probably less than for other more solid tumours types due to the large fluid component in craniopharyngiomas.

Taking the arguments above together:

A. CRT studies tend to include substantially larger tumour volumes and

B. Larger tumour volumes require higher doses for local control, it is tempting to conclude that a somewhat lower CRT dose than 50 Gy would give the same local control as GKRS for similar tumour volumes. If this line of arguments is correct, the $\alpha / \beta$ from clinical data, will be larger than the ones presented in Figure 2 and hence even more close to the $\alpha / \beta$ presented in this study from in vitro data.

It is debated whether benign intracranial tumours benefit from fractionation since the $\alpha / \beta$ is thought to be similar as for neural tissue or $2 \mathrm{~Gy}$. This is generally supposed to reduce the beneficial effects of fractionation but if the clinical $\alpha / \beta$ is as high as observed in our study we have strong arguments to apply fractionated radiation regimens to improve the therapeutic ratio. It is however important to notice that improvements in RT are clearly needed.

Even though CRT has been used for craniopharyngiomas for more than 40 years, the toxicity risk for the anterior visual pathway and the hypothalamus has not been reduced with recent improvements in this technique. The major part of those structures is still included in the high dose field prescribed for the tumour and receives doses just below the maximum tolerance level $[6,39,48]$. Furthermore structures involved in neurocognition are still at risk [6]. Improvements could be made by using fractionation with Gamma Knife $®$ or similar technique. By this approach one could overcome the target volume restrictions of single fraction treatment, avoid critical doses to structures involved in neurocognition and reduce the radiation load on the visual pathway and hypothalamus. Radiobiological data such as presented in this study would then be needed to design new fractionation regimens.

\section{Conclusion}

The high $\alpha / \beta$ in this in vitro study indicates that the adamantinomatous craniopharyngioma is among early responding tissues and supports the clinical praxis of fractionated radiation. The radiosensitivity parameters, SF2 and $\bar{D}$, indicate that these cell strains are slightly more radiosensitive than the average radiosensitive cancer cell line. Although some correlation with in vivo data is found, improvements in presenting treatment parameters and results after radiation treatment and further in vitro studies are encouraged to validate this data

\section{References}

1. Yamini B, Narayanan M (2006) Craniopharyngiomas: an update. Expert Rev Anticancer Ther 6(Suppl 9): S85-S92.

2. Kahn EA, Gosch HH, Seeger JF, Hicks SP (1973) Forty-five years experience with the craniopharyngiomas. Surg Neurol 1(1): 5-12.

3. Paulus W, Honegger J, Keyvani K, Fahlbusch R (1999) Xanthogranuloma of the sellar region: a clinicopathological entity different from adamantinomatous craniopharyngioma. Acta Neuropathol (Berl) 97(4): 377-382.

4. Spoudeas HA, Saran F, Pizer B (2006) A multimodality approach to the treatment of craniopharyngiomas avoiding hypothalamic morbidity: a UK perspective. J Pediatr Endocrinol Metab 19 (Suppl 1): 447-451.

5. Kalapurakal JA (2005) Radiation therapy in the management of pediatric craniopharyngiomas--a review. Childs Nerv Syst 21(8-9): 808-816.

6. Merchant TE, Kiehna EN, Kun LE, Mulhern RK, Li C, et al. (2006) Phase II trial of conformal radiation therapy for pediatric patients with craniopharyngioma and correlation of surgical factors and radiation dosimetry with change in cognitive function. J Neurosurg 104(2 Suppl): 94-102.

7. Paulino AC, Mai WY, Chintagumpala M, Taher A, Teh BS (2008) Radiation-induced malignant gliomas: is there a role for reirradiation? Int J Radiation Oncology Biol Phys 71(5): 1381-1387.

8. Tomita $\mathrm{T}$ (2005) Editorial on current surgical management of craniopharyngiomas. Childs Nerv Syst 21(8-9): 604-605.

9. Hukin J, Visser J, Sargent M, Goddard K, Fryer C, et al. (2005) Childhood craniopharyngioma: Vancouver experience. Childs Nerv Syst 21(8-9): 758-765.

10. Kobayashi T, Kida Y, Mori Y, Hasegawa T (2005) Long-term results of gamma knife surgery for the treatment of craniopharyngioma in 98 consecutive cases. J Neurosurg 103(6 Suppl): 482-488.

11. Stafford SL, Pollock BE, Leavitt JA, Foote RL, Brown PD, et al. (2003) A study on the radiation tolerance of the optic nerves and chiasm after stereotactic radiosurgery. Int J Radiat Oncol Biol Phys 55(5): 1177. 1181.

12. Tomita T, Bowman RM (2005) Craniopharyngiomas in children: surgical experience at Children's Memorial Hospital. Childs Nerv Syst 21(8-9): 729-746.

13. Weiss M, Sutton L, Marcial V, Fowble B, Packer R, et al. (1989) The role of radiation therapy in the management of childhood craniopharyngioma. Int J Radiat Oncol Biol Phys 17(6): 1313-1321.

14. Regine WF, Mohiuddin M, Kramer S (1993) Long-term results of pediatric and adult craniopharyngiomas treated with combined surgery and radiation. Radiother Oncol 27(1): 13-21.

15. Green H, Kehinde O, Thomas J (1979) Growth of cultured human 


\section{Open Access Journal of Neurology \& Neurosurgery}

epidermal cells into multiple epithelia suitable for grafting. Proc Natl Acad Sci U S A 76(11): 5665-5668.

16. Ulfarsson E, Karstrom A, Yin S, Girnita A, Vasilcanu D, et al. (2005) Expression and growth dependency of the insulin-like growth factor I receptor in craniopharyngioma cells: a novel therapeutic approach. Clin Cancer Res 11(13): 4674-4680.

17. Puck TT, Marcus PI (1956) Action of x-rays on mammalian cells. J Exp Med 103(5): 653-666.

18. Sinclair WK (1966) Biophysical Aspects of Radiation Quality. Lyon: IAEA, UAE, pp. 862-866.

19. Curtis SB (1976) The OER of mixed high- and low-LET radiation. Radiat Res 65(3): 566-572.

20. Taylor J (1986) Calculating the mean inactivation dose. Radiation Research 108(1): 112.

21. Fertil B, Dertinger H, Courdi A, Malaise EP (1984) Mean Inactivation Dose: A Useful Concept for Intercomparison of Hunam Cell Survival Curves. Radiation Research 99: 73-84.

22. Withers $H$ (1985) Biologic basis for altered fractionation schemes. Cancer 55: 2086-2095.

23. Habrand JL, Ganry O, Couanet D, Rouxel V, Levy-Piedbois C, et al. (1999) The role of radiation therapy in the management of craniopharyngioma: a 25-year experience and review of the literature. Int J Radiat Oncol Biol Phys 44(2): 255-263.

24. Fowler JF (2008) Optimum overall times II: Extended modelling for head and neck radiotherapy. Clinical Oncology 20(2): 113-126.

25. Fertil B, Malaise EP (1981) Inherent cellular radiosensitivity as a basic concept for human tumor radiotherapy. Int J Radiation Oncology Biol Phys 7(5): 621-629.

26. Deacon J, Peckham MJ, Steel GG (1984) The radioresponsivenss of human tumours and the initial slope of the cell survival curve. Radiother Oncol 2(4): 317-323.

27. Deschavanne JP, Fertil B (1996) A review of human cell radiosensitivity in vitro. Int J Radiat Oncol Biol Phys 34(1): 251-266.

28. West CML, Elyan SAG, Berry P, Cowan R, Scott D (1995) Intrinsic radiosensitivity as a predictor of patient response to radiotherapy. $\mathrm{Br} \mathrm{J}$ Radiol 68(812): 197-203.

29. Taghian A, Suit H, Pardo F, Gioioso D, Tomkinson K, et al. (1992) In vitro intrinsic radiation sensitivity of glioblastoma multiforme. Int J Radiat Oncol Biol Phys 23(1): 55-62.

30. Weichselbaum RR, Rotmensch J, Ahmed-Swan S, Beckett MA (1989) Radibiological chracterization of 53 human tumor cell lines. Int J Radiat Biol 56(6): 553-560.

31. Shrieve DC (2006) Basic Principles of Radiobiology applied to Radiotherapy of Benign Intracranial Tumors. Neurosurg Clin N Am 17(2 April): 67-78.

32. Perrry A, Stafford SL, Suman VJ, Lohse CM (1998) The prognostic significance of MIB-1, p53, and DNA flow dytometry in completely resected primary meningiomas. Cancer 82 (11): 2262-2269.

33. Cafer S, Bayromoglu I, Uzum N, Yilmaz M, Memis L, et al. (2007) Expression and clinical significance of Ki-67, oestrogen and progesterone receptors in acoustic neuroma. J Laryngol Otol 122(2): $1-3$.
34. Raghavan R, Dickey WT, Margraf LR, White CL, Coimbra C, et al. (2000) Proliferative activity in craniopharyngiomas: clinicopathological correlations in adults and children. Surg Neurol 54(3): 241-247.

35. Losa M, Vimercati A, Acerno S, Barzaghi RL, Mortini P, et al. (2004) Correlation between clinical characteristics and proliferative activity in patients with craniopharyngioma. J Neurol Neurosurg Psychiatry 75(6): 889-892.

36. Kreil W, Luggin J, Fuchs I, Weigl V, Eustacchio S, et al. (2005) Long term experience of gamma knife radiosurgery for benign skull base meningiomas. J Neurol Neurosurg Psychiatry 76(10): 1425-1430.

37. Kobayashi T, Kida Y, Mori Y (2001) Long-term results of stereotactic gamma radiosurgery of meningiomas. Surg Neurol 55(6): 325-231.

38. Prasad D, Steiner M, Steiner L (2000) Gamma Surgery for vestibular schwannoma. J Neurosurgery 92(5): 745-759.

39. Combs SE, Thilmann C, Huber PE, Hoess A, Debus J, et al. (2007) Achievement of long-term local control in patients with craniopharyngiomas using high precision stereotactic radiotherapy. Cancer 109(11): 2308-2314.

40. Bentzen SM, Ruifrok AC, Thames HD (1996) Repair capacity and kinetics for human mucosa and epithelial tumors in the head and neck: clinical data on the effect of changing the time interval between multiple fractions per day in radiotherapy. Radiother Oncol 38(2): 89101.

41. Ang KK, Thames HD, Peters LJ (1997) Altered fractionation schedules. In: Peres CA, Brady LW, editors. Principles and practice of radiation oncology. Philadelphia: Lippincott, pp. 119-43.

42. Withers HR (1997) Biological basis of radiation therapy. In: Peres CA, Brady LW, editors. Principles and practice of radiation oncology. $\left(3^{\text {rd }}\right.$ Edn), New York: JP Lippincott-Raven, pp. 79-118.

43. Gasinska A, Fowler JF, Lind B, Urbanski K (2004) Influence of Overall Treatment Time and Radiobiological Parameters on Biologically Effective Doses in Cervical Cancer Patients Treated with Radiation Therapy Alone. Acta Oncological 43(7): 657-666.

44. Daşu A, Fowler JF (2005) Comments on 'Comparison of in vitro and in vivo $\alpha / \beta$ ratios for prostate cancer'. Phys Med Biol 50(6): L1-L4.

45. Ågren Cronqvist A-K, Källman P, Turesson I, Brahme A (1995) Volume and heterogeneity dependence of the dose-response relationship for head and neck tumors. Acta Oncological 34(6): 851-860.

46. Saitoh JI, Sakurai H, Suzuki Y, Muramatsu H, Ishikawa H, et al. (2002) Correlations between in vivo tumor weight, oxygen pressure, 31P NMR spectroscopy, hypoxic microenvironment marking by beta-D-iodinated azomycin galactopyranoside (beta-D-IAZGP), and radiation sensitivity. Int J Radiat Oncol Biol Phys 54(3): 903-909.

47. Fischer EG, Welch K, Belli JA, Wallman J, Shillito JJ, et al. (1985) Treatment of craniopharyngiomas in children: 1972-1981. J Neurosurg 62(4): 496-501.

48. Minniti G,Saran F, Traish D, Soomal R, Sardell S, et al. (2007) Fractionated stereotactic conformal radiotherapy following conservative surgery in the control of craniopharyngiomas. Radiother Oncol 82(1): 90-95.

49. Ulfarsson E, Lindquist C, Roberts M, Rahn T, Lindquist M, et al. (2002) Gamma knife radiosurgery for craniopharyngiomas: long-term results in the first Swedish patients. J Neurosurg 97(Suppl 5): 613-622. 
Your next submission with Juniper Publishers will reach you the below assets

- Quality Editorial service

- Swift Peer Review

- Reprints availability

- E-prints Service

- Manuscript Podcast for convenient understanding

- Global attainment for your research

- Manuscript accessibility in different formats ( Pdf, E-pub, Full Text, audio)

- Unceasing customer service

Track the below URL for one-step submission http://juniperpublishers.com/online-submission.php 